\title{
Further Results on Dual Domination in Graphs
}

\author{
V.Lavanya, D. S. T. Ramesh, N.Meena
}

\begin{abstract}
Let $G=(V, E)$ be a simple graph. A set $S \subseteq V(G)$ is a dual dominating set of $G$ (or bi-dominating set of $G$ ) if $S$ is a dominating set of $G$ and every vertex in $S$ dominates exactly two vertices in $V$-S. The dual-domination number $\gamma_{d u}(G)$ (or bi-domination number $\gamma_{b i}(G)$ ) of a graph $G$ is the minimum cardinality of the minimal dual dominating set (or dual dominating set). In this paper dual domination number and relation with other graph parameters are determined.

Keywords: Domination, dual-domination, chromatic number and connectivity.
\end{abstract}

\section{INTRODUCTION}

Let $G(V, E)$ be a simple, connected graph where $V(G)$ is its vertex set and $E(G)$ is its edge set. The degree of any vertex $v$ in $\mathrm{G}$ is the number of edges incident with $\mathrm{v}$ and is denoted by deg v. The minimum degree of a graph is denoted by $\delta(\mathrm{G})$ and the maximum degree of a graph $\mathrm{G}$ is denoted by $\Delta(G)$. A vertex of degree 1 is called a pendent vertex. In this paper, dual domination number with other parameters are determined. For graph theoretic notations, Harary [1] and Gray chartand [2] are referred to.

\section{PRELIMINARIES}

Definition 2.1:[1] The chromatic number $\chi(\mathrm{G})$ is defined as the minimum $\mathrm{n}$ for which $\mathrm{G}$ has an $\mathrm{n}$-coloring. A graph $\mathrm{G}$ is $\mathrm{n}$-colorable if $\chi(\mathrm{G}) \leq \mathrm{n}$ and is n-chromatic if $\chi(\mathrm{G})=\mathrm{n}$.

Definition 2.2:[1] The connectivity $\kappa=\kappa(G)$ of a graph $G$ is the minimum number of points whose removal results in a disconnected or trivial graph.

Definition2. 3:[5] A set $S \subseteq V(G)$ is a dual dominating set of $G$ if $S$ is a dominating set of $G$ and every vertex in $S$ dominates exactly two vertices in $\mathrm{V}-\mathrm{S}$.

Revised Manuscript Received on February 05, 2020.

* Correspondence Author

V.Lavanya*, Research Scholar, Department of Mathematics, Nazareth Margoschis College, Pillaiyanmanai,Thoothukudi-628617, Affiliated to Manonmaniam Sundaranar University, Abishekapatti, Tirunelveli-627 012, TamilNadu, India. mukeshlavan75@gmail.com.

D.S.T.Ramesh, Department of Mathematics, Nazareth Margoschis College, Pillaiyanmanai,Thoothukudi-628617, Affiliated to Manonmaniainm Sundaranar University, Abishekapatti, Tirunelveli-627 012, TamilNadu, India. dstramesh@gmail.com

N.Meena, Department of Mathematics, The M.D.T Hindu College, Pettai, Tirunelveli- 627010,, Affiliated to Manonmaniam Sundaranar University, Abishekapatti, Tirunelveli-627012, TamilNadu, India. meenamdt@gmail.com

(C) The Authors. Published by Blue Eyes Intelligence Engineering and Sciences Publication (BEIESP). This is an open access article under the CC BY-NC-ND license (http://creativecommons.org/licenses/by-nc-nd/4.0/)
Remark 2.4: The dual domination number $\gamma_{d u}(G)$ of a graph $\mathrm{G}$ is the minimum cardinality of all minimal dual dominating sets. The maximum cardinality of a dual dominating set of $G$ is called the upper dual domination number of $G$ and it is denoted by $\Gamma_{d u}(\mathrm{G})$.

Theorem 2.5[5]: Let $G$ be a connected graph, If $G=K_{n}$ then $\gamma_{d u}(G)=\mathrm{n}-2$.

\section{MAIN RESULT}

Theorem 3.1: For any connected graph $\mathrm{G}$ with $\mathrm{n} \geq 5$ vertices, $\gamma_{\mathrm{du}}(\mathrm{G})+\chi(\mathrm{G}) \leq 2 \mathrm{n}-2$ and the bound is sharp if and only if

$\mathrm{G} \cong \mathrm{K}_{\mathrm{n}}$.

Proof: Let $\mathrm{G}$ be a connected graph with $\mathrm{n} \geq 5$ vertices. We know that $\chi(\mathrm{G}) \leq \mathrm{n}$ and by theorem $[1.5], \gamma_{\mathrm{du}}(\mathrm{G}) \leq \mathrm{n}-2$. Hence $\gamma_{\mathrm{du}}(G)+\chi(G) \leq 2 n-2$. Suppose $G$ is isomorphic to $K_{n}$. Then clearly $\gamma_{\mathrm{du}}(\mathrm{G})+\chi(\mathrm{G})=2 \mathrm{n}-2$. Conversely, let $\gamma_{\mathrm{du}}(\mathrm{G})+\chi(\mathrm{G})=2 \mathrm{n}-2$.

Case(i): Suppose $\chi(G)=n-r, r \geq 1$. Since $\gamma_{d u}(G)+\chi(G)=2 n$ $-2, \gamma_{\mathrm{du}}(\mathrm{G})=\mathrm{n}+\mathrm{r}-2$, a contradiction.

Case(ii): Suppose $\gamma_{\mathrm{du}}(\mathrm{G})=\mathrm{n}-\mathrm{r}, \mathrm{r} \geq 3$. Since

$\gamma_{\mathrm{du}}(\mathrm{G})+\chi(\mathrm{G})=2 \mathrm{n}-2, \chi(\mathrm{G})=\mathrm{n}+\mathrm{r}-2, \mathrm{r} \geq 3$, a contradiction. From both cases it is observed that $\gamma_{\mathrm{du}}(\mathrm{G})+$ $\chi(\mathrm{G})=2 \mathrm{n}-2$ is possible only if $\gamma_{\mathrm{du}}(\mathrm{G})=\mathrm{n}-2$ and $\chi(\mathrm{G})=\mathrm{n}$. Hence $\mathrm{G}$ is isomorphic to $\mathrm{K}_{\mathrm{n}}$.

Theorem 3.2: For any connected graph $G$ with $n \geq 3$ $\gamma_{d u}(G)+\Delta(G) \leq 2 n-3$

Proof: Let $G$ be a connected graph with $n \geq 5$ vertices. We know that for any connected graph $G, \Delta(G) \leq n-1$. Since $\gamma_{b i}(G) \leq \mathrm{n}-2, \gamma_{d u}(G)+\Delta(\mathrm{G}) \leq 2 \mathrm{n}-3$.

Example 3.3: Consider the following graph $G$ is given in the following figure 1

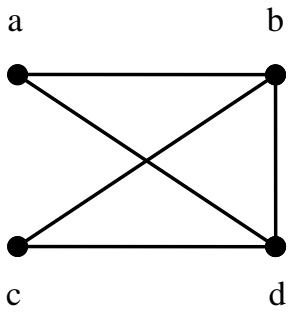

Figure1

Let $S_{1}=\{a, c\}$ and $S_{2}=\{b, d\}$, every vertex of the set $\mathrm{S}_{\mathrm{i}}, 1 \leq \mathrm{i} \leq 2$ dominates exactly two vertices in $\mathrm{V}-\mathrm{S}_{\mathrm{i}}$. Hence $\mathrm{S}_{\mathrm{i}}, 1 \leq \mathrm{i} \leq 2$ are the dual dominating set of $\mathrm{G}, \gamma_{d u}(G) \leq 2$. Since $\mathrm{G}$ is not isomorphic to either $\mathrm{C}_{3}$ or $\mathrm{P}_{3}, \gamma_{d u}(G) \geq 2$. Hence $\gamma_{d u}(G)=2$ and $\Delta(G)=3, \gamma_{d u}(G)+\Delta(G)=5=2 n-3$.

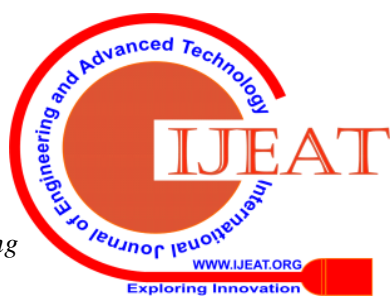




\section{Further Results on Dual Domination in Graphs}

Theorem 3.4: Let $G$ be a graph of order $n \geq 5$. Then $\gamma_{\mathrm{du}}(\mathrm{G})+$ $\gamma_{\mathrm{du}}(\bar{G}) \leq 2 \mathrm{n}-6$ and the bound is sharp.

Proof: Case(1): Suppose $\gamma_{\mathrm{du}}(\mathrm{G})=\mathrm{n}-2$. Let $\mathrm{S}$ be a $\gamma_{\mathrm{du}}-$ set. Let $\mathrm{V}-\mathrm{S}=\{\mathrm{u}, \mathrm{v}\}$, the two vertices $\mathrm{u}$ and $\mathrm{v}$ may or may not be adjacent with both $\mathrm{u}$ and $\mathrm{v}$ in $\mathrm{G}$. Let $\mathrm{H}=\langle s\rangle$. Hence $\bar{G}=\bar{H} \cup \mathrm{K}_{2}$ or $\bar{H} \cup 2 \mathrm{~K}_{1}$. Since $\mathrm{K}_{2}$ and $\mathrm{K}_{1}$ do not have dual dominating set, $\bar{G}$ has no dual dominating set.

Subcase(1a): Suppose $\gamma_{\mathrm{du}}(G)=\mathrm{n}-3$. Since $\gamma_{\mathrm{du}}(\bar{G}) \neq \mathrm{n}-1$, $\gamma_{\mathrm{du}}(\mathrm{G})+\gamma_{\mathrm{du}}(\bar{G}) \neq 2 \mathrm{n}-4$.

Subcase(1b): Suppose $\gamma_{\mathrm{du}}(G)=\mathrm{n}-4$. Since $\gamma_{\mathrm{du}}(\bar{G}) \neq \mathrm{n}, \gamma_{\mathrm{du}}(G)$ $+\gamma_{\mathrm{du}}(\bar{G}) \neq 2 \mathrm{n}-4$

Subcase(1c): Suppose $\gamma_{\mathrm{du}}(G)=n-r, r \geq 5$. Since $\gamma_{\mathrm{du}}(\bar{G}) \neq \mathrm{n}+\mathrm{s}, \mathrm{s} \geq 1, \gamma_{\mathrm{du}}(\mathrm{G})+\gamma_{\mathrm{du}}(\bar{G}) \neq 2 \mathrm{n}-4$.

From the cases (1), (1a) and (1b), $\gamma_{d u}(G)+\gamma_{\mathrm{du}}(\bar{G}) \neq 2 \mathrm{n}-4$. Case(2): Suppose either $\gamma_{d u}(G)$ or $\gamma_{\mathrm{du}}(\bar{G})$ is equal to $\mathrm{n}-2$. As in case(1) dual dominating set doesnot exist for $G$ or $\bar{G}$.

Subcase(2a): Suppose $\gamma_{d u}(G)=n-4$. Since $\gamma_{\mathrm{du}}(\bar{G}) \neq \mathrm{n}-1$. Hence $\gamma_{d u}(G)+\gamma_{\mathrm{du}}(\bar{G}) \neq 2 \mathrm{n}-5$.

Subcase(2b): Suppose $\gamma_{d u}(G)=n-r, r \geq 5$. Since $\gamma_{\mathrm{du}}(\bar{G}) \neq \mathrm{n}$ $+\mathrm{s}, \mathrm{s} \geq 0$. Hence $\gamma_{d u}(\mathrm{G})+\gamma_{\mathrm{du}}(\bar{G}) \neq 2 \mathrm{n}-5$.

case(3): Suppose $\gamma_{d u}(G)=\mathrm{n}-5$ and $\gamma_{\mathrm{du}}(\bar{G}) \neq \mathrm{n}-1$. Hence $\gamma_{d u}(\mathrm{G})+\gamma_{\mathrm{du}}(\bar{G}) \neq 2 \mathrm{n}-6$.

Subcase(3a): Suppose $\gamma_{d u}(G)=\mathrm{n}-\mathrm{r}, \mathrm{r} \geq 6$ and $\gamma_{\mathrm{du}}(\bar{G}) \neq \mathrm{n}+$ $\mathrm{s}, \mathrm{s} \geq 0$. Hence $\gamma_{d u}(\mathrm{G})+\gamma_{\mathrm{du}}(\bar{G}) \neq 2 \mathrm{n}-6$.

Case(4): Let $G=C_{5}$ and $\bar{G}$ is also $C_{5}$ and $\gamma_{\mathrm{du}}\left(C_{5}\right)=2$. Hence $\gamma_{d u}(G)+\gamma_{\text {du }}(\bar{G})=4=2 n-6$.

From all the cases $\gamma_{d u}(\mathrm{G})+\gamma_{\mathrm{du}}(\bar{G}) \leq 2 \mathrm{n}-6$.

Remark 3.5: Let $|\mathrm{V}(\mathrm{G})|=4$. $\mathrm{G}$ has a dual dominating set if and if $\mathrm{G}$ is isomorphic to $\mathrm{C}_{4}, \mathrm{~K}_{4}$ and $\mathrm{K}_{4}-\mathrm{e}$. Hence $\bar{G}=2 \mathrm{~K}_{2}$, $4 \mathrm{~K}_{1}$ and $\mathrm{K}_{2} \cup 2 \mathrm{~K}_{1}$ respectively. Hence $\bar{G}$ has no dual dominating set.

Remark 3.6: Let $|\mathrm{V}(\mathrm{G})|=3$. $\mathrm{G}$ has a dual dominating set if and if $\mathrm{G}$ is isomorphic to $\mathrm{P}_{3}$ and $\mathrm{C}_{3}$. Hence $\bar{G}=3 \mathrm{~K}_{1}$ and $\mathrm{K}_{2}$ $\cup \mathrm{K}_{1}$ respectively. Hence $\bar{G}$ has no dual dominating set.

Theorem 3.7: Let $\mathrm{G}$ be a connected graph with $\mathrm{n} \geq 3$ vertices, $\gamma_{d u}(G)+\kappa(G) \leq 2 n-3$ and the bound is sharp if and only if $\mathrm{G}$ is isomorphic to $\mathrm{K}_{\mathrm{n}}$.

Proof: Let $\mathrm{G}$ be a connected graph with $\mathrm{n} \geq 3$. We know that $\kappa(\mathrm{G}) \leq \mathrm{n}-1$ and $\gamma_{d u}(\mathrm{G}) \leq \mathrm{n}-2$. Hence $\gamma_{d u}(\mathrm{G})+\kappa(\mathrm{G}) \leq 2 \mathrm{n}$ -3 . Suppose $G$ is isomorphic to $K_{n}$. Then clearly $\gamma_{d u}(G)+$ $\kappa(\mathrm{G})=2 \mathrm{n}-3$. Conversly, Let $\gamma_{d u}(\mathrm{G})+\kappa(\mathrm{G})=2 \mathrm{n}-3$. This is possible only if $\gamma_{d u}(G)=n-2$ and $\kappa(G)=n-1$. Hence $G$ is isomorphic to $\mathrm{K}_{\mathrm{n}}$.

Theorem 3.8: Let $\mathrm{G}$ be a connected graph with $\mathrm{n} \geq 4$ vertices. Let $\mathrm{S}$ be a minimum dual dominating set of $\mathrm{G}$. If $\kappa(\mathrm{G})=\mathrm{n}-2$ or $\mathrm{n}-1, \Delta(\mathrm{G})=\mathrm{n}-1, \chi(\mathrm{G})=\mathrm{n}-1$ or $\mathrm{n}$, and $\operatorname{diam}(\mathrm{G})$ $=2$ or 1 iff $|S|=n-2$ and $\langle s\rangle$ is complete graph.

Proof: Let $\mathrm{G}$ be a connected graph with $\mathrm{n} \geq 4$ vertices. $\mathrm{S}=\left\{\mathrm{v}_{1}, \mathrm{v}_{2}, \ldots, \mathrm{v}_{\mathrm{n}-2}\right\}$ is the dual dominating set of $\mathrm{G}$ and $<S>$ is complete graph.

Case(i): Suppose the vertices $\mathrm{v}_{\mathrm{n}-1}$ and $\mathrm{v}_{\mathrm{n}}$ belong to $\mathrm{V}-\mathrm{S}$ is adjacent with each other. Then clearly $\kappa(\mathrm{G})=\mathrm{n}-1, \Delta(\mathrm{G})=$ $\mathrm{n}-1, \chi(\mathrm{G})=\mathrm{n}$, and $\operatorname{diam}(\mathrm{G})=1$.

Case(ii): Suppose the vertices $\mathrm{v}_{\mathrm{n}-1}$ and $\mathrm{v}_{\mathrm{n}}$ belong to $\mathrm{V}-\mathrm{S}$ not adjacent with each other. Then clearly $\kappa(\mathrm{G})=\mathrm{n}-2$,

$\Delta(\mathrm{G})=\mathrm{n}-1, \chi(\mathrm{G})=\mathrm{n}-1$, and $\operatorname{diam}(\mathrm{G})=2$.

Conversely,

Case(i): Suppose $\kappa(G)=n-1$ then $G$ is isomorphic to $K_{n}$.

Clearly $\Delta(\mathrm{G})=\mathrm{n}-1, \chi(\mathrm{G})=\mathrm{n}$, and $\operatorname{diam}(\mathrm{G})=1$.

Let $V(G)=\left\{v_{1}, v_{2}, \ldots, v_{n}\right\} . S=\left\{v_{1}, v_{2}, \ldots, v_{n-2}\right\}$ is the minimum dual dominating set of $\mathrm{G}$. $|\mathrm{S}|=\mathrm{n}-2$ and $\langle S>$ is complete graph.

Case(ii): Suppose $\chi(\mathrm{G})=\mathrm{n}-1$ then $\mathrm{G}$ is isomorphic to $\mathrm{K}_{\mathrm{n}}$ e. Clearly $\Delta(\mathrm{G})=\mathrm{n}-1, \kappa(\mathrm{G})=\mathrm{n}-2$, and $\operatorname{diam}(\mathrm{G})=2$. Let $V(G)=\left\{\mathrm{v}_{1}, \mathrm{v}_{2}, \ldots, \mathrm{v}_{\mathrm{n}}\right\} . \mathrm{S}=\left\{\mathrm{v}_{1}, \mathrm{v}_{2}, \ldots, \mathrm{v}_{\mathrm{n}-2}\right\}$ is the minimum dual dominating set of $G$. The vertices $v_{n-1}$ and $v_{n}$ not adjacent with each other. $|\mathrm{S}|=\mathrm{n}-2$ and $\langle S\rangle$ is complete graph.

\section{CONCLUSION}

In this paper, dual domination number with chromatic number, connectivity and Nordhaus-Gaddum type result are discussed .

\section{REFERENCES}

1. Harary.F, Graph theory, Addison-Wesley Publishing Company Reading, Mass (1972).

2. Gary Chartand, Ping Zhang, Introduction to Graph theory, McGraw Hill Education (India) Private Limited, New Delhi (2006)

3. Teresa W.Haynes, Routlege, Domination in graphs: Volume 2 Advanced Topics,(2017)

4. V.Lavanya ${ }^{1}$, D. S. T. Ramesh ${ }^{2}$ and N. Meena ${ }^{3}$, Bi-domination in Graphs, International Journal of Emerging Technologies and Innovative Research(2019), 424-427

5. V.Lavanya ${ }^{1}$, D. S. T. Ramesh ${ }^{2}$ and N. Meena ${ }^{3}$, Bi-domination in Corona Related Graphs, Journal of Computer and Mathematical Sciences, Vol.10(11),1650-1653 November 2019(An International Research Journal), www.compmath-journal.org ISSN 0976-5727 (Print) ISSN 2319-8133 (Online).

\section{AUTHORS PROFILE}

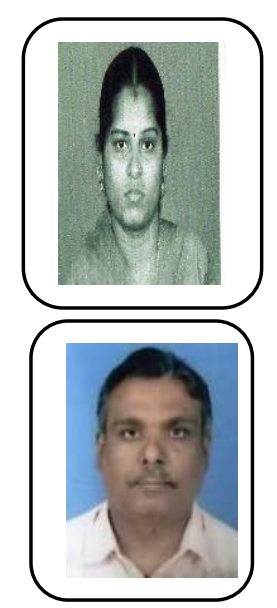

College, Sawyerpuram.

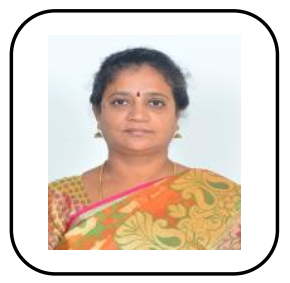

V.Lavanya M.Sc., B.Ed., Mphil., Research scholar, Department of Mathematics in Nazerth Margochis College, Pillayanmanai, Tuticorin, Tamil Nadu. Published 5 papers in National and International Journals. Presented three papers in National and International conferences.

Dr. D.S.T.Ramesh, M.Sc., M.Phil., Ph.D., He is an Associate Professor of Mathematics in Nazerth Margochis College, Pillayanmanai, Tuticorin, Tamil Nadu. He has 31 years of teaching experience. He guided 8 Ph.D."s and 5 M. Phil.. His area of specialization is Graph Theory. He published 50 research papers in National and International Journals. He was invited as a resource person for some National conferences organized by Sacred Heart College, Tirtupattur and Pope's

Dr.N.Meena, M.Sc., M.Phil., B.Ed., Ph.D., she is an Assitant Professor of Mathematics in The M.D.T.Hindu college, Tirunelveli, Tamilnadu. She presented 41 Research papers in National and International conferences. She published 32 Research papers in National and International Journals. She completed one U.G.C Minor Research project. Her area of specialization is Graph Theory. 